\title{
Complete Research Paper: Implementation of an Introductory Module on Biogeotechnics in a Freshman Engineering Course
}

\section{Dr. Jean S. Larson, Arizona State University}

Jean Larson has a Ph.D. in Educational Technology, postgraduate training in Computer Systems Engineering, and many years of experience teaching and developing curriculum in various learning environments. She has taught technology integration and teacher training to undergraduate and graduate students at Arizona State University, students at the K-12 level locally and abroad, and various workshops and modules in business and industry. Dr. Larson is experienced in the application of instructional design, delivery, evaluation, and specializes in eLearning technologies for training and development. Her research interests focus on efficient and effective online learning, and how instructors are prepared to teach in digital environments. She coordinates outreach events for the Center for Bio-mediated and Bio-inspired Geotechnics (CBBG) with local school districts and organizations, various centers on the ASU campus, and summer programs for teachers, high school students and undergraduates. She also develops CBBG curriculum for learners at the K-12, college, and professional development levels.

Medha Dalal, Arizona State University

Dr. Wilhelmina C. Savenye, Arizona State University

Dr. Wilhelmina "Willi" C. Savenye is a professor and program leader in Educational Technology at Arizona State University. She previously taught at the University of Texas at Austin and San Diego State University. She earned her M.Ed. and Ph.D. in Educational Technology from ASU, and B.A/ in Anthropology from the University of Washington. Dr. Savenye focuses on instructional design and evaluation of technology-based and online learning systems, employing both quantitative and qualitative research methodologies. She has published over 70 articles and book chapters; made over 140 conference presentations and workshops in the U.S., Europe and Asia; been awarded numerous grants, and has produced many digital learning programs. She serves as Editor of the Journal of Applied Instructional Design. She has served on the editorial boards of journals including Educational Technology: Research and Development and the Quarterly Review of Distance Education, and reviews for additional journals. She serves on the editorial board for the Encyclopedia of Educational Technology and has held elected leadership positions. Dr. Savenye's instructional design and evaluation work has been conducted in such diverse settings as school districts, museums, botanical gardens, zoos, universities, corporations, and Army tank maintenance training.

\section{Dr. Claudia Elena Zapata, Arizona State University}

Claudia Zapata is Associate Professor in the School of Sustainable Engineering and the Built Environment. Dr. Zapata's research interest is in the area of unsaturated soil behavior. She has focused her work on laboratory and field characterization of problematic soils; applications related to the hydro-thermal and mechanical behavior of soils due to static and repeated loading; modeling fluid flow and volume change of soils applied to pavement structures and residential foundation systems; and the assessment of the environmental effects on soil behavior. Current research activities include the study of the effects of thermal gradients on airfield pavement structures and the characterization of fiber-reinforced clay materials. She is currently overviewing the Engineering Education and Diversity program of the NSF Engineering Research Center called Center for Bio-mediated and Bio-inspired Geotechnics. Dr. Zapata has authored more than 50 technical publications; is the Chair of the Transportation Research Board committee on the Behavior of Unsaturated Geomaterials and active member of several committees for TRB and the ASCE. Consulting expertise include the evaluation of airfield design procedures, forensic investigations of pavement failures, and the assessment of environmental effects on pavement design; for several companies and agencies, including the Louisiana State DOT, US Army Corps of Engineers, AMEC and Parsons.

\section{Dr. Nasser Hamdan, Center for Bio-mediated \& Bio-inspired Geotechnics}

Nasser Hamdan is the Industrial Collaboration and Innovation Director (Industry Liaison Officer) and Assistant Research Professor at the Center for Bio-mediated and Bio-inspired Geotechnics. Dr. Hamdan's 
expertise includes biogeotechnical engineering and biogeochemical processes for ground improvement and remediation. His research activities involve experimentation and analytical testing related to induced carbonate precipitation using biological processes and macromolecules such as enzymes and biopolymers. $\mathrm{He}$ is involved in various projects directed towards the improvement of the bulk mechanical properties of soil, surficial soil stabilization, sustainable building materials, facilitated mineral precipitation and environmental remediation.

\section{Prof. Edward Kavazanjian Jr., Arizona State University}

Professor Kavazanjian is a Regents Professor and the Ira A. Fulton Professor of Geotechnical Engineering at Arizona State University (ASU). He is also Director of the Center for Bio-mediated and Bio-inspired Geotechnics, a National Science Foundation Gen-3 Engineering Research Center. He has Bachelor and Master of Science degrees from M.I.T. and a PhD from the University of California at Berkeley in Civil Engineering, specializing in Geotechnical Engineering. He was on the faculty at Stanford University for 7 years and then spent 20 years in engineering practice before joining the faculty at ASU in 2004 . He was elected to the National Academy of Engineering in 2013 for his work on the mechanical properties of municipal solid waste, analysis and design of waste containment systems, and geotechnical earthquake engineering. He is a past-President of the Geo-Institute of the American Society of Civil Engineers, representing the 11,000+ geotechnical engineers that are members of ASCE. 


\title{
Implementation of an Introductory Module on Biogeotechnics in a Freshman Engineering Course
}

\begin{abstract}
This Complete Research paper describes a one-lesson instructional module introducing biogeotechnical engineering that has been developed by an interdisciplinary team of engineers and educators for use in freshman-level introduction to engineering courses. The primary aims in developing the module were to educate incoming engineering students regarding the field of biogeotechnics and motivate them to pursue it further. Expanding research and innovation in this emerging area requires providing students with an understanding of the principles of this new paradigm for developing sustainable solutions in geotechnical engineering applications. Field trials of the instructional module, which included pre- and post-assessments, were conducted in two sections of a freshman engineering course at a large southwestern university in the United States. Evaluation data were collected regarding student knowledge gains and attitudes. Both the overall gain in technical knowledge and positive attitudes toward the field of biogeotechnical engineering were reflected in participant responses. With the advent and development of this new field, this work represents a pioneering effort in the biogeotechnical engineering education space. Looking ahead, the study could contribute toward longitudinal research in understanding the best practices of interdisciplinary approaches to developing engineering instruction.
\end{abstract}

\section{Introduction}

This study is situated in the context of an interdisciplinary collaboration via an engineering and education instructional design team with the goal of educating freshman students regarding the new field of biogeotechnical engineering. The interdisciplinary team was formed under the NSFfunded Engineering Research Center for Bio-mediated and Bio-inspired Geotechnics (CBBG). The Center is a four university partnership between Arizona State University (ASU), Georgia Institute of Technology (GT), New Mexico State University (NMSU), and University of California, Davis (UCD). The Center concentrates on developing sustainable, environmentallyfriendly, and cost-effective approaches to the design, operation, and maintenance of geotechnical aspects of civil infrastructure systems.

A CBBG Curriculum Committee was formed with the purpose of providing an avenue to capture technical insight on newly-created educational materials and activities by experts in the field. All developed curriculum materials went through a formal and thorough examination for accuracy and clarity before dissemination. The Curriculum Committee is comprised of one faculty member and one student researcher from each CBBG partner university, with the Education and Pre-College Directors as co-chairs. Feedback from all committee members is then incorporated into the module, assessments, and supporting materials before being finalized.

This paper provides an overview of the study's use of interdisciplinary design approaches, the instructional module's content, and methods of formative evaluation employed in the field trials. Also covered are lessons learned from the field trials, the revision process, and plans for disseminating the module to partner universities in the future. 


\section{Background}

Biogeotechnics is a rapidly emerging branch of geotechnical engineering that focuses on learning from nature to help address engineering challenges. Although many freshman engineering students may have already decided to pursue one of the main branches of engineering (e.g., mechanical, electrical, civil, or chemical), many are still exploring the sub-fields and specializations within each branch (Shamma \& Purasinghe, 2015). Exposing undergraduates to research being conducted in biogeotechnics, along with various career options available, which are often dependent upon these specializations, may help students make a more informed decision in selecting their educational path. Duderstadt (2008) states that the increase in ongoing technological advances, "require highly interdisciplinary engineering teams characterized by broad intellectual span rather than focused practice within traditional disciplines” (p.3). This trend will require that current and future engineering students increasingly broaden their technical perspectives to pursue interdisciplinary fields of study. In response to these demands, the authors have developed a module entitled, "Introduction to Biogeotechnical Engineering," for presentation in freshman-level courses that are designed to introduce the broader field of civil engineering. The present module extends learning about the area of geotechnical engineering to the freshman year (typically not taught until the junior or senior year), including the new subfield of biogeotechnical engineering.

\section{Materials}

As a starting point for the module's content, the interdisciplinary team from education and engineering used nine previously developed and delivered webinars created by graduate student members of the CBBG Student Leadership Council (SLC) and the education team. These webinar presentations were created to provide an overview of the principles of biogeotechnics and current research in this area to participants in the 2016 CBBG Summer Programs, which included high school students, undergraduate students, and K-14 STEM teachers. The nine presentations covered the following topics: Introduction to Geotechnical Engineering, Introduction to Biogeotechnics, Microbially Induced Calcite Precipitation (MICP), Root-Inspired Foundations, Enzymatically Induced Calcite Precipitation (EICP), Ant-Inspired Excavations, Microbial Ecology, Biofilms, and Zeolite Sorption. Additional resources, such as books, images, and presentations, were contributed by engineering faculty that helped to provide sufficient support for creating the technical content of the lecture.

The one-lesson module was designed to be easily incorporated into undergraduate introduction to engineering courses. The lecture materials include a one-page instructor handout, pre- and postpresentation surveys, and a customizable 50- to 90-minute PowerPoint presentation with interactive elements to engage the students. The instructor handout (Figure 1) covers brief information on the background, organization and timeline for delivering the module, instructions for administering assessments, supplies needed for the presentation, and suggestions for effective delivery. 


\section{CBBG Introduction to Biogeotechnical Engineering Instructor Handout}

\section{Background}

This instructional module is developed to motivate and educate freshman civil engineering students to learn about, become interested in, and consider careers in, biogeotechnical engineering. The module is meant to be a teacher-led, in class, customizable lecture for a 50 to 90-minute-long session for introductory engineering courses.

Organization and timeline:

1. Pre-survey

2. Instructional time with in-class student activities

3. Post-survey
6 to 8 minutes

50 to 75 minutes

8 to 10 minutes

Assessments:

Links to the online assessment instruments are provided within the presentation. Participants may use their laptops, tablets, or smartphones to take the surveys; however, it is suggested to keep some paper copies of the assessments for backup.

\section{Supplies needed for the instructional delivery of the module}

- $\quad$ Classroom equipped with computer and speakers, projector, and screen

- $\quad$ PowerPoint slides, pre-loaded onto a USB or shared drive

- $\quad$ Paper copies of pre and post assessments as backup

- $\quad$ Students should come prepared with paper and pencil

- $\quad$ Pictures of implemented applications, samples of bio-cemented sand, or other visual aid to share

- $\quad$ Optional demonstrations in biogeotechnical engineering (Liquefaction and Surficial Soil Stabilization)

Suggestions for effective delivery

- $\quad$ Review instructional slides (along with notes provided below each slide) ahead of time

- To view notes during instructional delivery, either start PowerPoint in presentation mode $\rightarrow$ presenter view, or print out the notes before class

- Modify slide 35 to include elective course numbers specific to your institution

- $\quad$ If short on time, skip slides 29 to 34

- If there is extra time in the class period, show the following video created by Geoengineer.org: Fascinating Geotechnical Engineering News that Happened in 2016 -https://www.youtube.com/watch?v=eOBwkdB4rU0

- Contact Dr. Jean Larson at jean.larson@asu.edu or (480) 965-7804 if you have any questions or concerns.
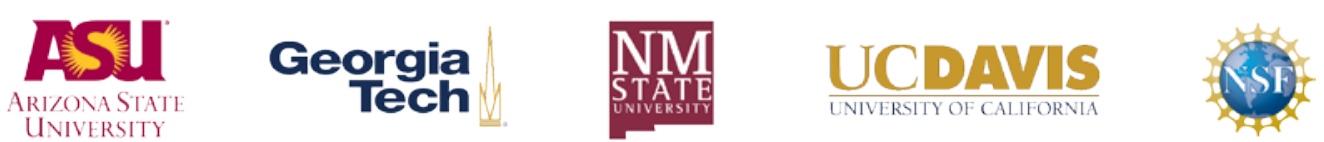

Figure 1. Instructor Hand-Out 
Instructor notes are included below each slide of the presentation for additional clarification, consistency, and support. Links to the online pre- and post- survey assessments are provided within the presentation, so that participants can have access using laptops, tablets, or smartphones. To prepare for the possibility that some students may have technical problems or do not have a mobile device, instructors are advised to print additional paper copies of the assessments for backup. The surveys assess knowledge gain, attitude, and the effectiveness of materials and delivery, as outlined in Table 1 in the following pages.

The learning objectives related to this module were as follows: Upon completion of the Introduction to Biogeotechnical Engineering presentation, students will be able to: 1) Define the field of biogeotechnical engineering, describe its fundamental principle, and name various disciplines involved in biogeotechnics, 2) Differentiate between bio-inspired and bio-mediated processes, and 3) Describe opportunities available in the field and acquire a positive attitude toward biogeotechnical research and careers.

The growing number of sub-disciplines and related fields within civil engineering can be confusing for engineering students when trying to understand how they are all related. Shayan and Abdulla (2008, July) suggest guiding students with a "science tree" for a clearer vision of how the various fields are related. A flowchart illustrating the hierarchy of civil engineering disciplines, as related to geotechnical engineering and other sub-disciplines, is shared for the purpose of situating the content. The geotechnical engineering specialty area is defined, along with a general description of the work involved. Students are then asked to participate in an interactive discussion with their neighbor to identify examples of various types of work performed by a geotechnical engineer that may include building with earth, remediation problems, or restoring ecosystems; and then share ideas with the class. Next, various examples of human-made geotechnical systems are identified, as well as problems with these systems (Figure 2). The class is prompted to discuss possible solutions and ways to prevent these problems in a small group activity.
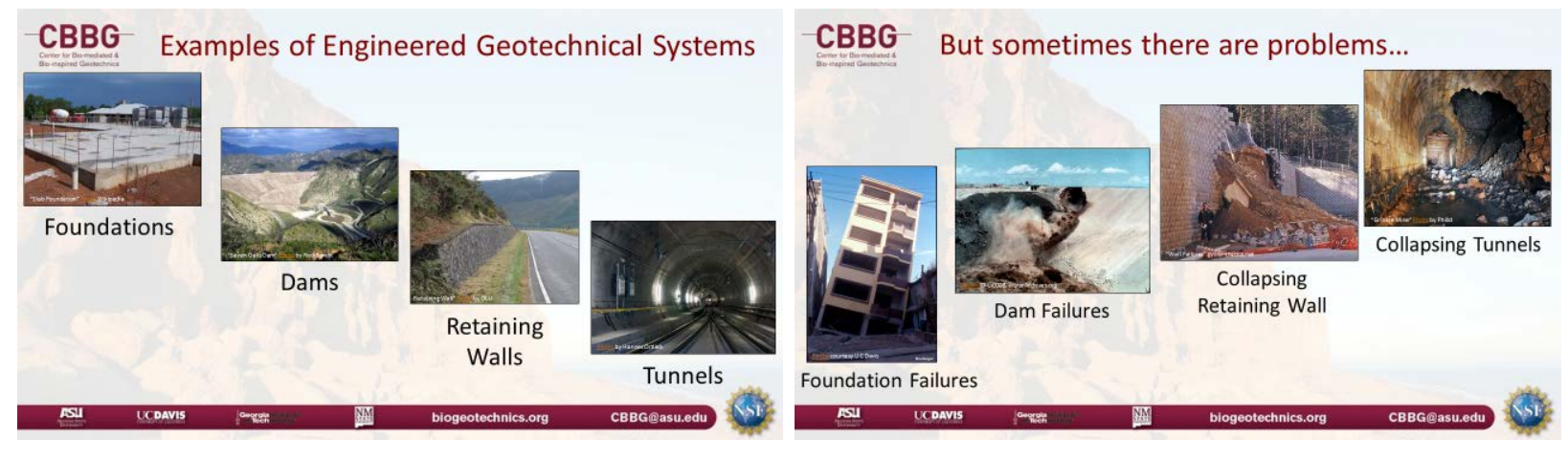

Figure 2. Examples of Geotechnical Systems

The next section of the module focuses on the fundamental principle behind biogeotechnics: to study and learn from nature. The instructor is asked to discuss examples of familiar natural systems that are durable and resilient, such as safe and efficient ant tunnels, bamboo trees that survive storms by bending, and cemented soil deposits that withstand earthquakes and erosion without slope failures. The multidisciplinary nature of biogeotechnical engineering is highlighted 
in an expanded version of the civil engineering hierarchy flowchart shown earlier. A formal definition of biogeotechnics is provided with further descriptions of how a biogeotechnical engineer learns from nature to develop new technologies for sustainable applications (Figure 3).

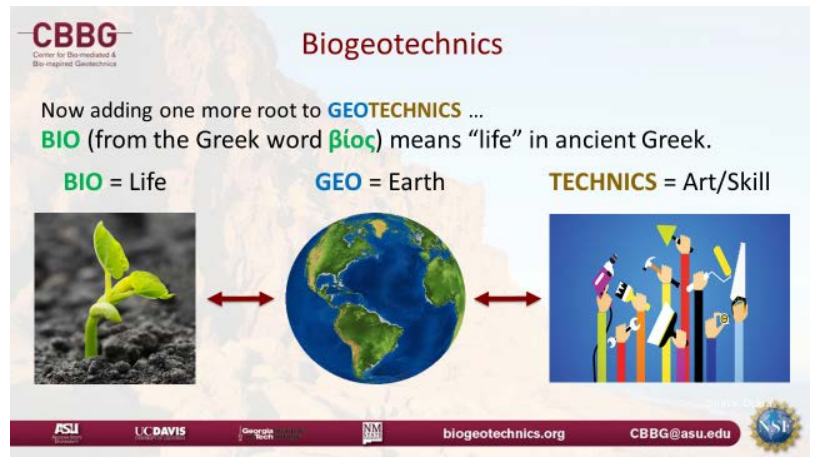

$$
\text { CBBG What is Biogeotechnics? }
$$

Biogeotechnics is the study and use of processes, reactions, and mechanisms found in nature to solve engineering problems related to earth systems.

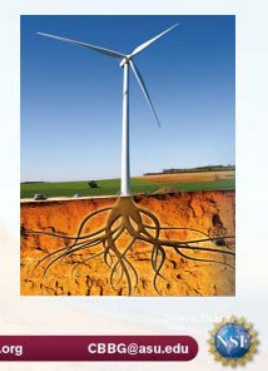

Figure 3. Defining Biogeotechnics

Next, two approaches of employing nature to develop applications in biogeotechnics are introduced: bio-mediated and bio-inspired processes. A bio-mediated process occurs when living organisms are used to affect changes in order to meet design objectives. This might happen, for example, when a biological or biochemical solution is used to implement or accelerate the process to improve existing material. When inspiration is taken from nature to develop an abiotic design or approach, it is considered a bio-inspired process. Further explanation on bio-inspired foundation construction is seen in a short video embedded in the presentation (Figure 4).
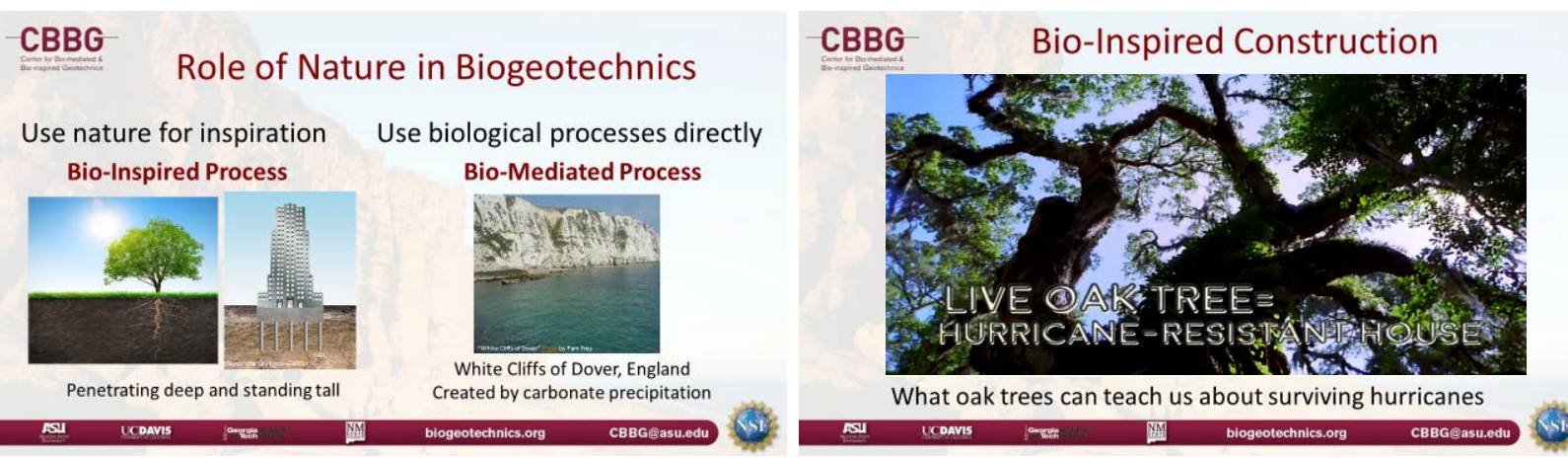

Figure 4. Bio-Inspired and Bio-Mediated Processes

Several geotechnical problems are presented, along with their current best-known solutions and a discussion of their disadvantages. Bio-mediated and bio-inspired solutions that are presently being researched as more cost-effective and sustainable alternatives are offered. Excavation technologies are covered, including discussion on how these technologies relate to bio-mediated and bio-inspired processes. A fast motion video of ants tunneling illustrates the potential for developing a safer and more efficient bio-inspired excavation technology.

As a knowledge check, a short reflection activity is included that asks students to write down their own definition for biogeotechnical engineering and to list some processes in nature that may help civil engineers develop sustainable solutions. A few student volunteers are asked to 
share their reflections with the class. This discussion leads into the next section, which covers possible reasons for pursuing a degree in the field of biogeotechnics.

The industry partners of the CBBG, in collaboration with Center researchers, work towards the common goal of transforming research findings into practice. Exposure to various professional practices and what it "looks like” to be an engineer are typically included in first-year engineering courses (Chesler, Arastoopour, D’Angelo, Bagley, \& Shaffer, 2013). As stated by Goodhew (2010), "If these career paths are foreseeable by students part-way through their programme, then this must influence their motivation towards and commitment to professional engineering” (p.8). Various industries associated with biogeotechnical engineering are listed and discussed within the lecture to give students a better idea of the numerous opportunities in the field (Figure 5).

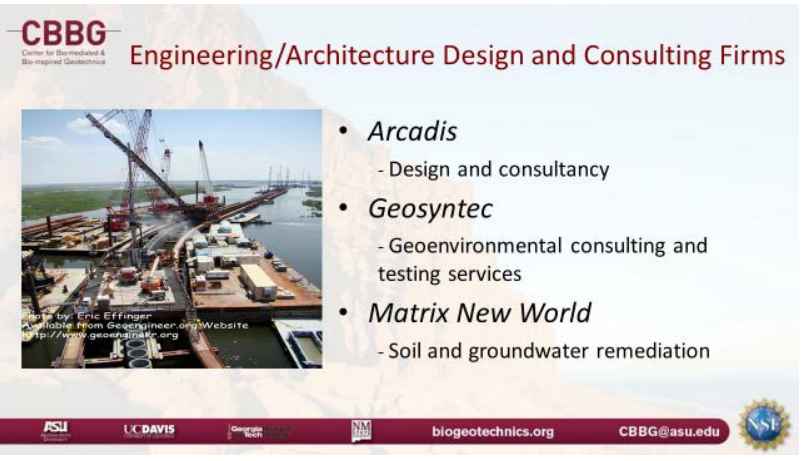

\section{CBBG Geotechnical Specialty Contractors}

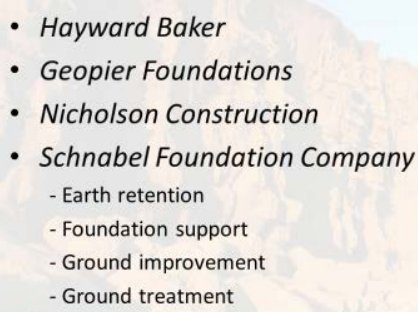

Figure 5. Examples of Industry Slides

Participants may notice that job opportunities can overlap significantly between different types of firms, which can be very beneficial when seeking to carry over experience gained from one job to the next. It is emphasized that students interested in multi-disciplinary research may also benefit from the predicted shortfall of geoscientists and the rising salaries in this area (Wilson, 2016).

Finally, to prepare for the future job opportunities, various educational opportunities are presented in the module. Students are invited to consider working in a CBBG laboratory as part of a research team, interning over the summer with a CBBG industry partner, participating in a Vertically Integrated Project: http://www.vip.gatech.edu/ (undergraduate research experience available at some universities), or registering for geotechnical and/or environmental electives during their junior or senior year. There are also graduate school assistantships available for those interested in pursuing further research in the field.

All of the above mentioned materials were reviewed by the CBBG Curriculum Committee and recommendations from the team were incorporated for further improvement. The suggestions from the Curriculum Committee on improving the instructor handout (Figure 1) included adding a note asking students to record their thoughts during the lecture, clarifying the name used for the assessments (pre-survey assessment vs. pre-assessment), clarifying instructions on accessing presenter view in PowerPoint, and minor typos. Modifications made to the presentation included 
adding further details to the instructor notes on several slides, additional answer options to the activities, and increasing the size of some of the images.

To create a more impressive and informative lecture, it was also suggested to include a brief biogeotechnics hands-on activity, pictures of implemented applications, or at least examples of biogeotechnology to display, such as a bio-cemented column of sand. Two brief optional demonstrations related to biogeotechnical engineering, one on Soil Liquefaction (Larson, Gutierrez, Woolley, \& Savenye, 2015) and one on Surficial Soil Stabilization (Larson, He, Hamdan, \& Savenye, 2015), are included with the instructor materials. The phenomenon of liquefaction is briefly explained in the Soil Liquefaction one-page handout (Figure 6), and can be demonstrated using a shake table or even a tub of saturated sand. 


\section{Soil Liquefaction}

\section{Experiment in Biogeotechnical Engineering}

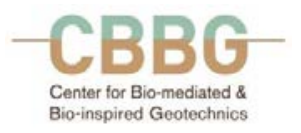

www.biogeotechnics.org

\section{What is Liquefaction?}

Liquefaction is when the shaking of an earthquake causes the soil to act and flow like a liquid. In a saturated soil's natural state, the particles stick together and do not move due to the friction between the soil particles. In a saturated soil, usually sand, all of the spaces in between the soil particles (also known as pore spaces) are filled with water. The water in the pore spaces cause water pressure to exist in the soil. An earthquake's shaking causes vibrations to occur which pushes the grains of sand and squeezes the soil. If the soil is saturated, the grains push on the water that is trapped in the pores. This increases the water pressure in the pore spaces and reduces the friction between particles, which cause the soil grains to lose contact with one another, and easily slide past each other. This gives the soil the ability to flow as if it were a liquid.

\section{Try this Liquefaction Experiment at home!}

1. Fill a plastic cup $3 / 4$ full with dry sand. Place four pennies in the sand to resemble vertical "walls" of a building. Simulate an earthquake by lightly tapping the cup on the counter being careful to not knock over the pennies. What happened to your "walls"?

2. Remove the pennies from the cup, pour out the sand and then fill a little less than half of the cup with water. Next, slowly refill the cup with your sand making sure to add enough sand to fully cover the water (i.e., no water should be visible). Replace the penny walls and recreate the earthquake. What happened this time?

This example shows how liquefaction can cause the soil underneath a structure to become unstable and cause damage indirectly beyond the direct hazard of the earthquake.

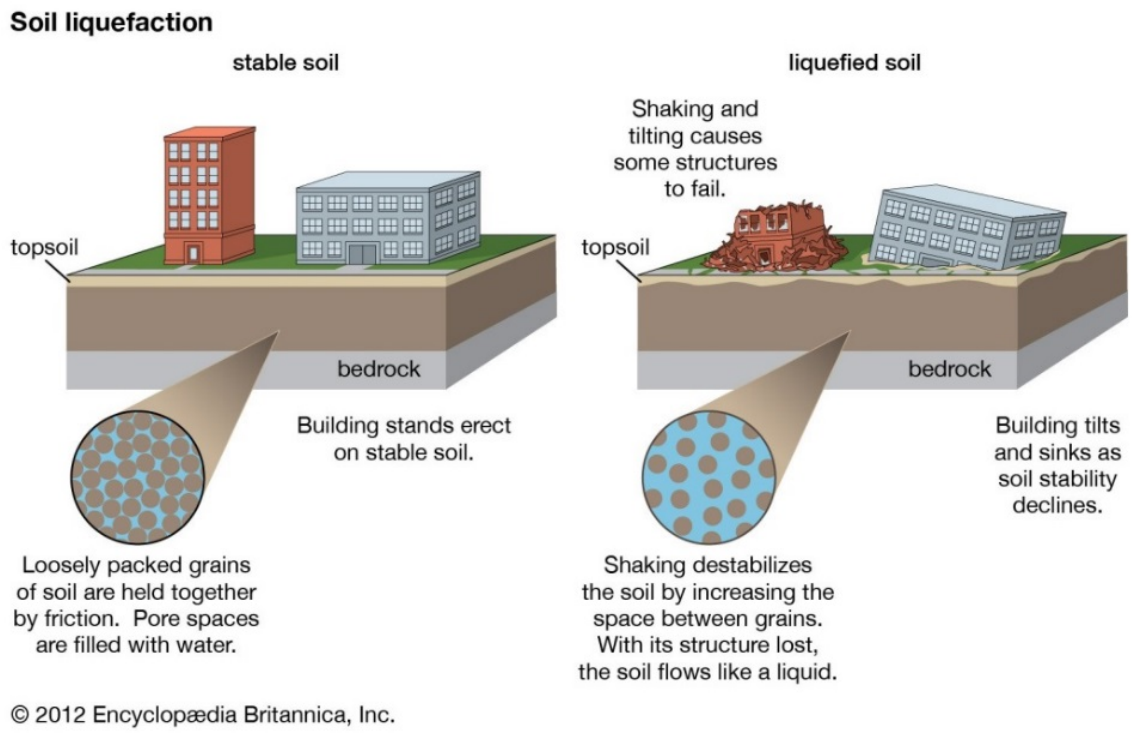

Soil Liquefaction [Art]. In Encyclopæedia Britannica. Retrieved from http://tinyurl.com/zdc6fd8
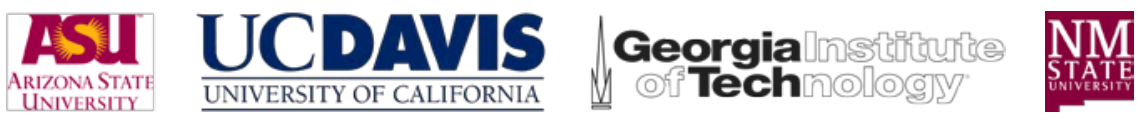

Figure 6. Soil Liquefaction Hand-Out

A natural method for preventing soil erosion is explained in the Surficial Soil Stabilization onepage handout (Figure 7), along with steps for experimenting with hydrogels. 


\title{
Surficial Soil Stabilization
}

\author{
Experiment in Biogeotechnical Engineering
}

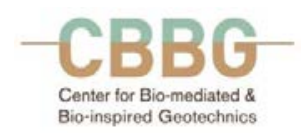

$\underline{\text { www. biogeotechnics.org }}$

How can we prevent damage due to soil erosion?

Surface soil particles are held together by various organic substances that act like a protective glue. When soils are disturbed (by humans, animals, wind, rain, etc.), the "glue” can be broken-up or washed away. Disturbing this top layer increases soil erosion, and can add large amounts of dust to the air and unwanted soil into our water. Airborne dust is an environmental pollutant that can be hazardous to human health and safety, and excess soil erosion can contaminate our drinking water.

What if we could find a natural way to stabilize surface soils by reforming a protective glue that can reduce erosion and dust? CBBG engineers and scientists are researching ways to add environmentally friendly materials, found in nature, to soil in order to help prevent the damaging effects of soil erosion.

\section{Try this Hydrogel Experiment at home!}

1. Purchase hydrogel (sodium polyacrylate, pronounced “poly-ak-rill-ate”): http://www.stevespanglerscience.com/store/water-gel-magic-slush-powder.html

2. Add 1/8 teaspoon of sodium polyacrylate powder into a clear plastic cup.

3. Slowly add water to the powder while gently stirring with a disposable spoon or fork until you notice a major change. Is the mixture a solid or a liquid? What does it feel like? How might adding a similar ingredient to soil make it more stable? (Optional) Add food coloring to the water.

Before: Loose, “unglued” sand

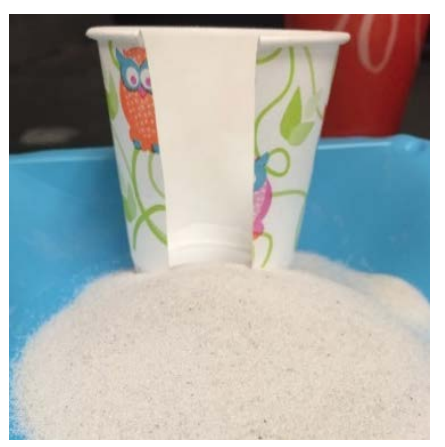

After: Sand surface is treated ("glued”) by hydrogel

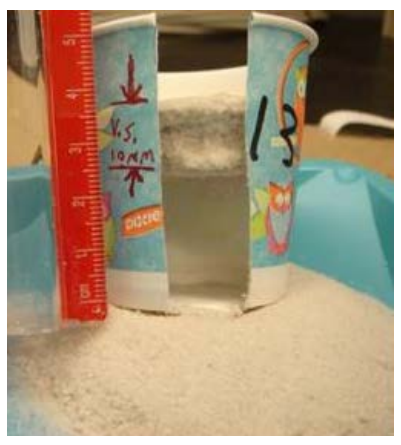

Safety Note: Water gel is non-toxic. Dispose of gel in the trash, not the sink.
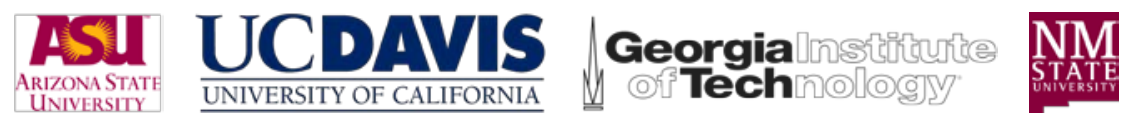

Figure 7. Surficial Soil Stabilization Hand-Out

Without these tangible models, it is feared that students may interpret the field of biogeotechnics as still in its infancy, and not something that they may currently pursue.

\section{Methods}

As part of the instructional design process, formative evaluation of the instructional materials was conducted throughout implementation to receive feedback and improve the designed material. Formative evaluation of the Introduction to Biogeotechnical Engineering module was conducted in November, 2016 in three sections of freshman-level courses required for undergraduate engineering students at Arizona State University. First, a small group pilot test was conducted in a course called "The ASU Experience," which is required by students in the 
Civil, Environmental, and Sustainable Engineering Program. This course covers topics such as problem solving approaches for sustainability challenges, overall social embeddedness, and benefits of interdisciplinary research. The module was delivered on November 2, 2016 by the CBBG Director to his own section of the course during one 50-minute class period. Data collected for this try out have been analyzed and presented in a different paper (Dalal, Larson, Zapata, Savenye, Hamdan, \& Kavazanjian, 2017).

Two field trials, the focus of this paper, were then conducted in two separate civil engineeringoriented sections of a course called "Introduction to Engineering," which is another required course for freshman engineering students. Introduction to the engineering design process, working in teams, engineering models, general information about the engineering profession as a whole, and other such topics are addressed in this course. Findings from each of these field trials are discussed below.

Field Trial 1. On November 4, 2016, the CBBG Deputy Director delivered the module to a colleague's section of the Introduction to Engineering course. This 50-minute section was attended by four male students and three female students.

Clearer guidelines were added to the slide's instructor notes for the first activity, which asks students to discuss thoughts on preventing problems with engineered geotechnical systems within a small group. When asked if the biogeotechnical solution provided on the animated slide (Figure 8) for fugitive dust is bio-mediated or bio-inspired, most students incorrectly guessed that it is bio-mediated.
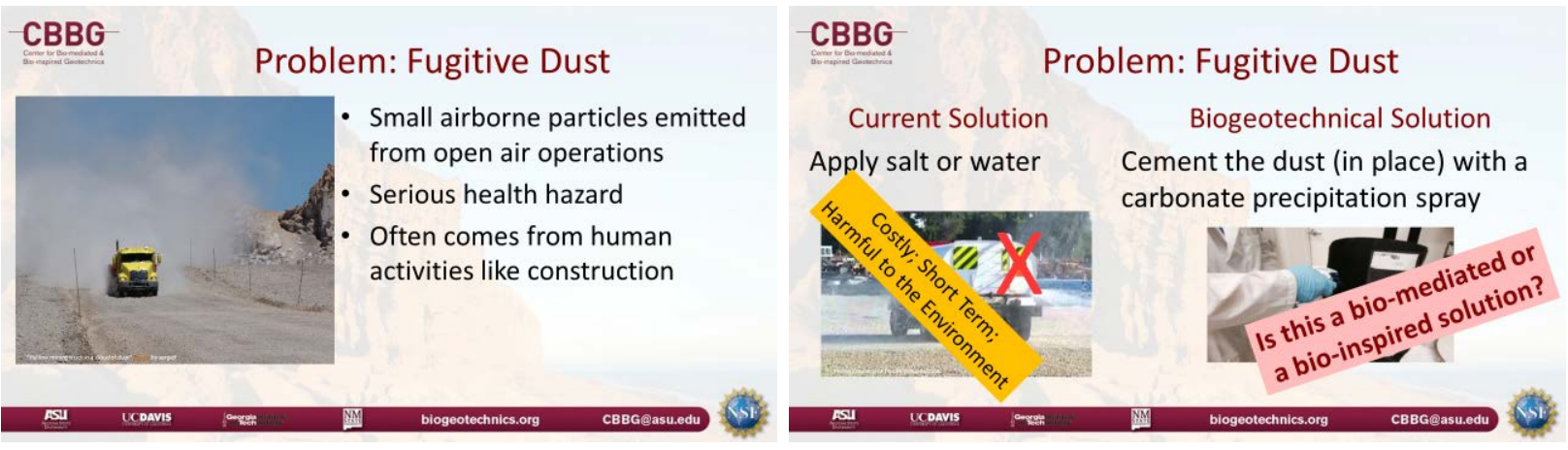

Figure 8. Sample Slides

The instructor explained that when live products like bacteria or fungus are used for the solution, it is bio-mediated. However, when using enzymes and other non-alive products to mimic a process done by nature, the solution is bio-inspired. These facts were added to the instructor notes below the slide in the presentation for further clarification.

All images included in the module were confirmed to have permission for use, and appropriate citations were added. One image without permission for use was replaced by a newly-created one by a member of the education team. Supplemental information was added to the instructor notes on relevant images in order to aid students in making real-world connections with the content. 
Additional changes were made to the instructor handout based on feedback from the presenter. These changes included adding suggestions to either start the PowerPoint in presenter view or print out the accompanied notes before class so they can be viewed during the lecture. Options for customizing the lecture based on class length and the presenter's own experiences were also added.

Field Trial 2. The Director of the CBBG delivered the Introduction to Biogeotechnical Engineering module on November 17, 2016 to a class of 33 students (26 males, 7 females). One change to the presentation since the last field trial was on the slides showing the civil engineering hierarchy. Previously, the hierarchy started with engineering, showing various branches of the field. Because undergraduate students already pursuing an engineering degree program are familiar with this aspect of the profession, the slides were modified to begin with civil engineering. Various relevant fields feeding into biogeotechnics, such as biology, geochemistry, plant sciences, etc., were added to highlight the multidisciplinary nature of the sub-discipline. Another minor change was made to the instructor hand-out, in regards to the timeline of the presentation. In previous field trials, the instructor was left with little to no time for administering the post-survey to the class. In order to remedy this, the instructor notes provide options for some material that may be skipped, while still covering the important content. In the case of the present field trial, the instructor did not skip any activities or the detailed slides on industry, and still completed the lecture with sufficient time to administer the post-survey.

\section{Response Rate}

Data from the field trials in the two freshman Introduction to Engineering sections were combined and analyzed. A total of 29 pre-surveys and 29 post-surveys, including questions in both open and closed form, were completed and analyzed.

\section{Survey Design}

The pre-survey includes a consent form and ten technical knowledge questions related to biogeotechnical engineering. Scoring guidelines and an answer key to the pre-survey are provided for the instructor. In addition, a scoring rubric was created for the final open-ended question on the pre-survey which asks, "How would you define biogeotechnical engineering?"

The post-survey also includes a consent form and questions that cover the following three domains: a) technical knowledge, b) attitude, and c) module feedback. The ten technical questions asked in the pre-survey are repeated in the post-survey. The post-survey also includes four attitude questions, using a Likert-type scale. Additional questions included in the postsurvey ask the students for their opinions regarding various aspects of the instructional module. Five of these evaluation questions are closed-ended in form, and three are open-ended. Table 1 presents all of the questions included in the pre- and post-surveys, and separately categorizes these questions within domains of inquiry and question type. 
Table 1

Domains of Inquiry, Question Type, and Corresponding Survey Questions

\begin{tabular}{|c|c|c|}
\hline $\begin{array}{l}\text { Domains } \\
\text { of Inquiry }\end{array}$ & $\begin{array}{l}\text { Type of } \\
\text { Question }\end{array}$ & Corresponding Survey Questions [Number] \\
\hline $\begin{array}{l}\text { Technical } \\
\text { Knowledge }\end{array}$ & $\begin{array}{l}\text { Multiple Choice } \\
{[1-8]}\end{array}$ & $\begin{array}{l}\text { The skill of building on, in, or with soil and rock is the specialty of... [1] } \\
\text { The main principle of biogeotechnical engineering is to... [2] } \\
\text { When we take ideas from our environment and apply them to the design and } \\
\text { modeling of engineering applications, it is a... [3] } \\
\text { When we study bacterial or microbial processes and apply them in engineering } \\
\text { applications, it is a... [4] } \\
\text { Which one of these options is one of the preferred biogeotechnical solution to } \\
\text { the problem of fugitive dust? [5] } \\
\text { A biofilm is a large mass of microbes attached to a surface. If you use a biofilm } \\
\text { to clog the soil and prevent seepage erosion in case of a dam failure, what type } \\
\text { of biogeotechnical solution would that be? [6] } \\
\text { An example of bio-mediated solution would be... [7] } \\
\text { Which of the following is NOT a job opportunity for a biogeotechnical } \\
\text { engineer? [8] } \\
\text { List } 3 \text { disciplines that are part of the multi-disciplinary field of biogeotechnics. } \\
\text { [9] } \\
\text { How would you define biogeotechnical engineering? [10] }\end{array}$ \\
\hline Attitude & $\begin{array}{l}\text { Likert-Type } \\
\text { Scale } \\
{[11-14]}\end{array}$ & $\begin{array}{l}\text { After going through the introductory lecture on biogeotechnial engineering, I } \\
\text { am... } \\
\text { Interested in taking additional classes in biogeotechnics. [11] } \\
\text { Interested in doing undergraduate research in biogeotechnics. [12] } \\
\text { Interested in biogeotechnical careers. [13] } \\
\text { Enthusiastic about biogeotechnical engineering. [14] }\end{array}$ \\
\hline $\begin{array}{l}\text { Module } \\
\text { Feedback }\end{array}$ & $\begin{array}{l}\text { Likert-Type } \\
\text { Scale } \\
{[15-17]} \\
\text { Rating Scale } \\
\text { [18-19] } \\
\text { Open-Ended } \\
\text { [20-22] }\end{array}$ & $\begin{array}{l}\text { Please give us your opinion about the introductory lecture to biogeotechnical } \\
\text { engineering. } \\
\text { I gained useful knowledge about biogeotechnics from the presentation. [15] } \\
\text { The group activities were engaging. [16] } \\
\text { The pictures on the slides helped me to learn. [17] } \\
\text { The amount of information presented for the length of the lecture was... [18] } \\
\text { How would you rate today's presentation overall? [19] } \\
\text { Comments? [20] } \\
\text { What did you like BEST about the presentation? [21] } \\
\text { Write below any SUGGESTIONS you have for making the introductory lecture } \\
\text { to biogeotechnical engineering more effective. [22] }\end{array}$ \\
\hline
\end{tabular}

\section{Results}

Technical Knowledge. The surveys for the current study included both closed and open-ended technical questions. Results from the eight quantitative questions were analyzed using descriptive statistics; the results from the two qualitative questions were double-blind scored using a common rubric. The same ten technical questions were included in both the pre-survey and the post-survey to identify a change, if any, in students' knowledge. The results of the technical section of the pre-survey shows that the overall score for the 29 students was $31.9 \%$. This score doubled in the post-survey, with the overall performance for 29 post-surveys 
increasing to $63.2 \%$, showing an overall gain of $98 \%$. The results of the technical knowledge section of the instruments for the first ten questions can be seen in Figure 9.

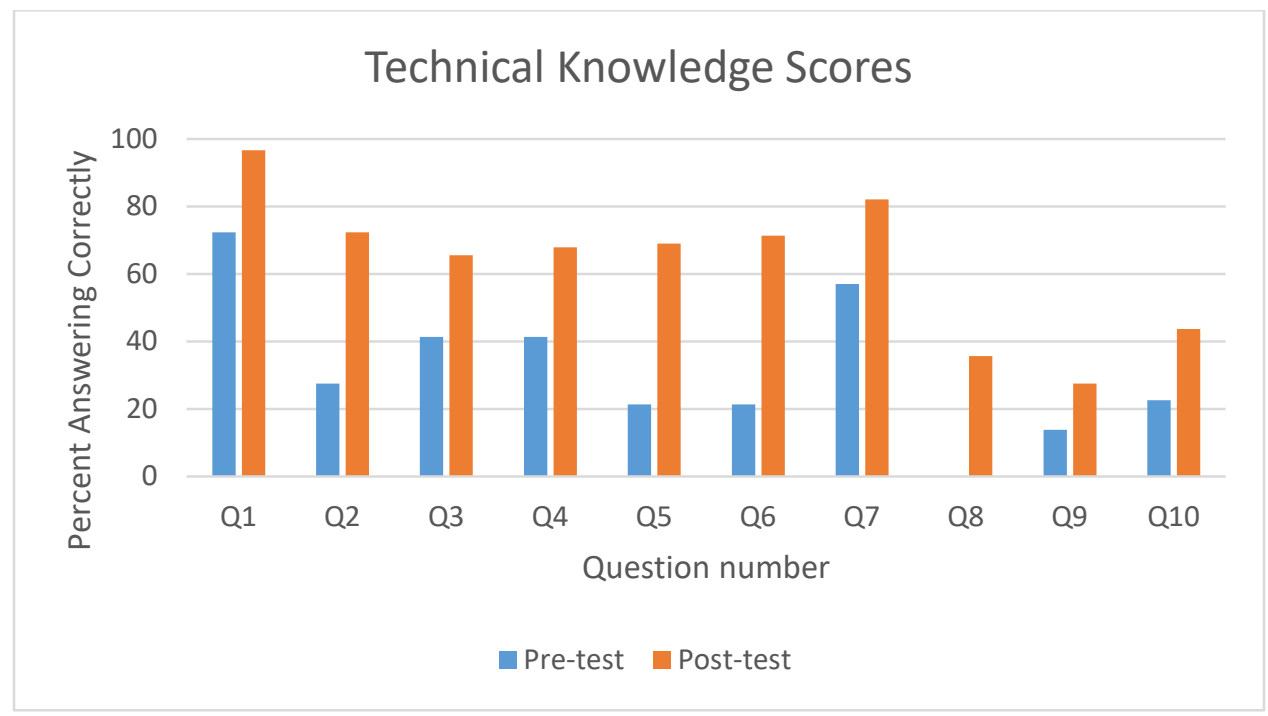

Figure 9. Technical Knowledge Scores

The 25 students that completed both the pre- and post-survey were matched and reviewed, however, no clear patterns emerged. Individual student growth will be something to examine in more detail once the materials are disseminated to the four partner universities and a larger audience. Although results do show an increase in knowledge on all ten technical questions between the pre-and post-surveys, it is yet unknown how the current interactive module format compares to traditional introductory lectures on the same material. Not only is there a lack of introductory lectures on the subject of biogeotechnical engineering, traditional lectures employed in introduction to civil engineering courses do not typically stress inter-disciplinarity, or involve highly structured, interactive activities. Regardless of the increase from the pre-survey scores, several of the post-survey scores were fairly low, which may be due to a negatively-worded survey question (Q8), or not giving enough examples (Q9), or even the need to spend more time on the definition of "biogeotechnical engineering" (Q10). Additional revisions will be made before distributing further.

Attitudes Toward Biogeotechnical Engineering. Students were asked about their attitudes toward biogeotechnical engineering upon completion of the module with items that employed a five-point Likert-type scale in the post-survey (from 1 = "Strongly Disagree" to 5 = "Strongly Agree"). Questions 11 - 14 began with the statement: "After going through the introductory lecture on biogeotechnical engineering, I am...", followed by four attitude statements. Participants indicated their agreement/disagreement for each of the items. Positive attitudes toward the field of biogeotechnical engineering were demonstrated by the majority of participants marking "Agree" or "Strongly Agree" to each of the statements. The responses indicated enthusiasm and interest in careers, undergraduate research and taking additional classes in the new field. These statements, along with the results, are displayed in Figure 10 below. 


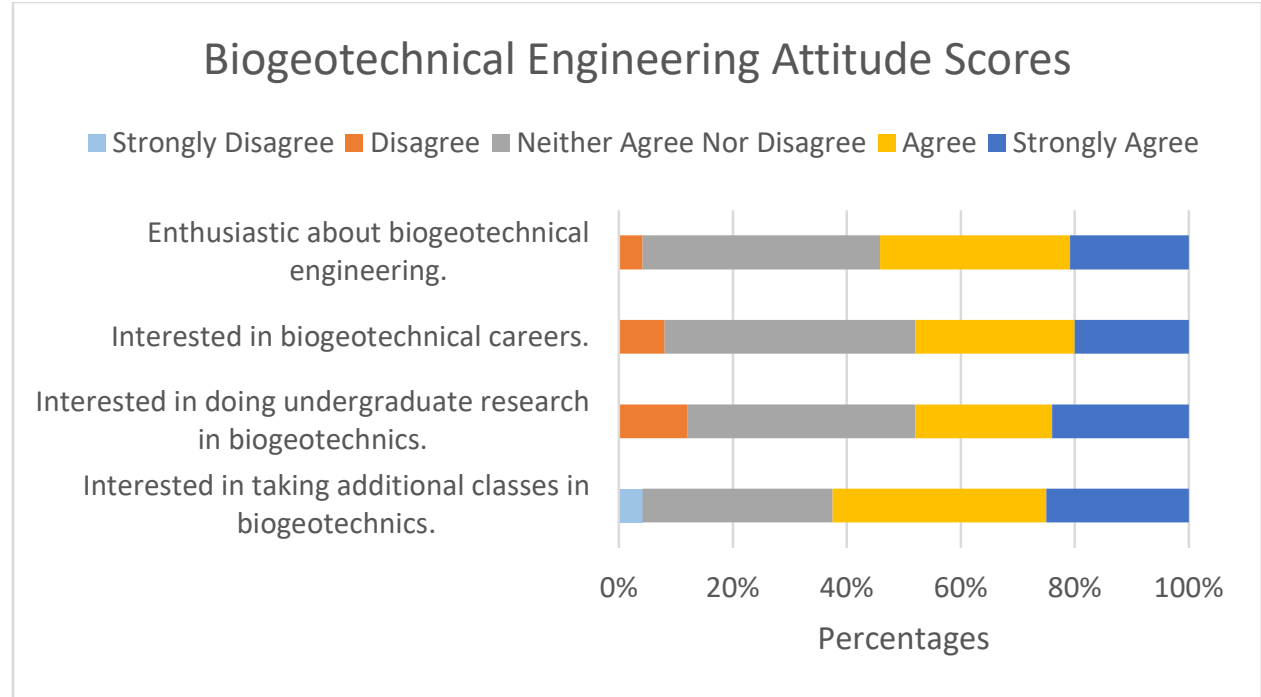

Figure 10. Attitude Scores Related to Biogeotechnical Engineering

Module Feedback. The instructional material for the introductory lecture on biogeotechnical engineering was evaluated in the post-survey by the students sharing their opinions using a fivepoint Likert-type scale (from 1 = "Strongly Disagree" to 5 = "Strongly Agree"). Although one participant skipped this section, the students assigned an average rating of 4.2 for "the pictures on the slides helped me to learn," and 4.2 for "I gained useful knowledge about biogeotechnics from the presentation.” The lowest rating of 3.8, which is still on the positive side of the scale, was given for the statement, "the group activities were engaging” (Figure 11). To improve the engagement with group activities, additional demonstrations and hands-on activities were added to the instructional materials for future deliveries of the module.

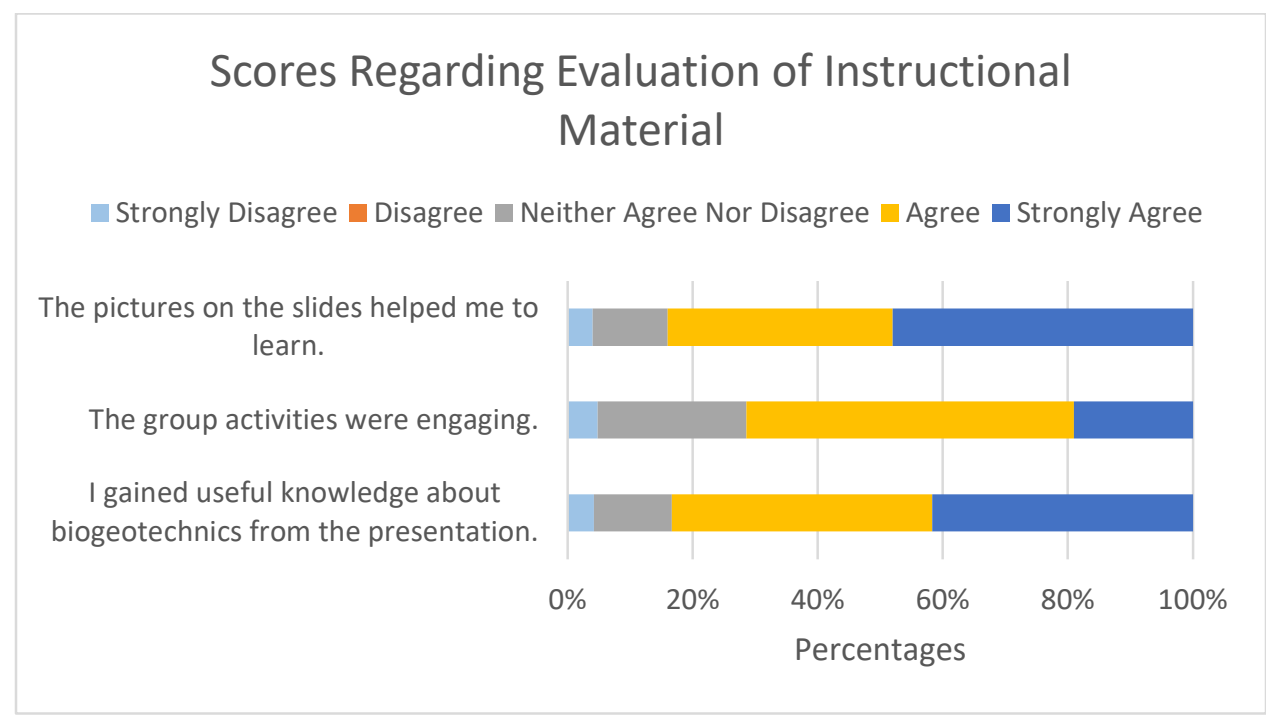

Figure 11. Attitude Scores Related to Evaluation of Instructional Material

The overall rating of the presentation was 4.3, indicating a "good" or "excellent" rating. Opinions on the amount of information presented for the length of the lecture were gathered. 
Twenty-seven of the participants responded that the amount of information was "just right," with only one student stating "too little” and one student stating "too much.”

Optional comments regarding the presentation included "Nice I get good information," and "Very well spoken and presented." When asked what the students liked best about the presentation, responses included the information presented, the presenter, the examples given, and the images. One student wrote, "I just thought example of the application of natural processes in engineering was really cool.” Another student appreciated the pertinent examples included in the module, as he wrote, "I liked how he gave specific examples on the topic." Participants also liked the overview of the field, the videos, the presenter's enthusiasm, and the introduction to this new sub-field of engineering. For example, one student said, "I liked the overview of the field. I also liked all the applications and uses that were explained." Another student wrote, "I liked what I learned about nature and how we have incorporated it into different projects.” When asked for suggestions to make the introductory module more effective, responses were all positive, and praising the material. For example, one participant stated, "I think it did its job fine and I thought it was engaging."

\section{Dissemination}

The next step for the developed and tested freshman introductory module is to disseminate the materials across the four CBBG partner universities for use in introduction to engineering undergraduate courses. These materials were designed to be adapted as needed, and can be incorporated in any order in an introductory class for undergraduates. Ultimately, the materials will be shared with national organizations, such as the American Geosciences Institute and TeachEngineering Digital Library.

The engineering and educational instructional design team has already begun development of several modules on biogeotechnical engineering for junior-level introduction to geotechnical engineering courses. One of the Center's partner universities will lead the effort to create materials for a senior-level design/technical elective course, and one of the newly-hired CBBG faculty is working on a graduate course in biogeotechnics. These materials will all go through a similar evaluation process before being disseminated to a wider audience.

\section{Lessons Learned}

Developing engineering education materials with this same collaborative team approach may be considered when creating new materials for engineering students. Although the content covered in the Introduction to Biogeotechnical Engineering module is new and not typically included in traditional introduction courses, the highly visual and interactive teaching approach can be used to improve any introductory lesson. Through the formative evaluation of materials, several pedagogical lessons were learned, such as the importance of including highly visual materials, interactive discussion activities throughout, organized instructional notes and handouts, hands-on demonstrations, and information on possible careers in the field. Another beneficial approach was used to grab the attention of the students by discussing a variety of real-world engineering problems that were easily relatable. For example, common geotechnical engineering problems were posed to the students, such as soil liquefaction: when loose, saturated soil experiences stress 
from earthquake motions and behaves like a flowing liquid. The current, best-known solutions of compaction or grouting to preventing this phenomenon are described, along with disadvantages to these methods. A much more sustainable, cost-effective, and bio-mediated solution is then presented and discussed. Sharing innovative ways to learn from nature and offering sustainable alternatives to current engineering problems can be an effective way to engage students and spark interest in this area of study.

There are several benefits that can be drawn from this study for engineering educators and researchers. A major benefit to including the various sub-disciplines in the field of civil engineering, along with career possibilities, in first-year engineering curricula may not only better prepare students in the geosciences, but may help guide their education and career path decisions.

\section{Conclusion}

The rapid increase in technological innovation and the present trend in the engineering profession to become more interdisciplinary will require current and future engineering students to become polymaths in the many overlapping fields. With the continual growth of the various sub-disciplines of engineering, it is important to support instructors with appropriate materials for engaging incoming students and encouraging further exploration in these fields. The results of this study indicate that those currently enrolled in an undergraduate civil engineering program are interested in learning more about biogeotechnical engineering, and even desire to take additional courses in the area. The introductory materials created are a starting point in establishing a body of knowledge for teaching fundamental concepts in interdisciplinary subfields of engineering.

\section{Acknowledgments}

This material is based upon work primarily supported by the National Science Foundation (NSF) under NSF Award Number EEC-1449501. Any opinions, findings and conclusions, or recommendations expressed in this material are those of the author(s), and do not necessarily reflect those of the NSF.

\section{References}

Chesler, N.C., Arastoopour, G., D’Angelo, C.M., Bagley, E.A., and Shaffer, D.W. (2013). Design of professional practice simulator for educating and motivating first-year engineering students. Advances in Engineering Education, 3(3), 1-29.

Dalal, M., Larson, J., Zapata, C., Savenye, W., Hamdan, N., \& Kavazanjian E. (2017). An Interdisciplinary Approach to Developing an Undergraduate Module on Biogeotechnical Engineering. In Proceedings of Society for Information Technology \& Teacher Education International Conference 2017 (pp. 1470-1475). Chesapeake, VA: Association for the Advancement of Computing in Education (AACE).

Duderstadt, J. J. (2008). Engineering for a changing world: A Roadmap to the future of engineering practice, research, and education. Ann Arbor: The Millennium Project, the 
University of Michigan. Retrieved from

http://milproj.ummu.umich.edu/publications/EngFlex_report/download/EngFlex\%20Report.pdf

Goodhew, P. (2010) Teaching engineering. Liverpool: UKCME.

Larson, J., Gutierrez, A., Woolley, M., Savenye, W. (2015). Soil Liquefaction: An Experiment in Biogeotechnical Engineering. Handout. Center for Bio-mediated and Bio-inspired Geotechnics (CBBG). Tempe, AZ.

Larson, J., He, X., Hamdan, N., Savenye, W. (2015). Surficial Soil Stabilization: An Experiment in Biogeotechnical Engineering. Handout. Center for Bio-mediated and Bio-inspired Geotechnics (CBBG). Tempe, AZ.

Shamma, J.E. \& Purasinghe, R. (2015). Introduction to Sub-Branches of Civil Engineering Fields through a Creative Freshmen Civil Engineering Design Course. ASEE Annual Conference \& Exposition, Seattle, WA, June 14-17, 2015. Washington D.C.: American Society for Engineering Education.

Shayan, Y.R. \& Abdulla, M. (2008, July). Design Based Teaching for Science and Engineering Students, Paper presented at the Conference on Canadian Design Engineering Network (CDEN’08), pp. 1-4, Halifax, Nova Scotia, Canada.

Wilson, C. (2016). Status of the Geoscience Workforce 2016. Report. American Geosciences Institute. Alexandria, VA. 